\title{
Students' Critical Incidents of Fairness in Classroom Assessment: An Empirical Study
}

\author{
A. Rasoolia, C. Deluca ${ }^{a}$, A. Rasegh ${ }^{b}, \&$ S. Fathi ${ }^{b}$ \\ ${ }^{\text {a}}$ Faculty of Education, Queen's University, Kingston, Canada \\ ${ }^{b}$ Institute for Advanced Studies in Basic Sciences, Iran
}

Full Citation:

Rasooli, A., DeLuca, C., Rasegh, A., \& Fathi, S. (2019). Students' Critical Incidents of Fairness in Classroom Assessment: An Empirical Study. Social Psychology of Education.

https://doi.org/10.1080/0969594X.2019.1593105
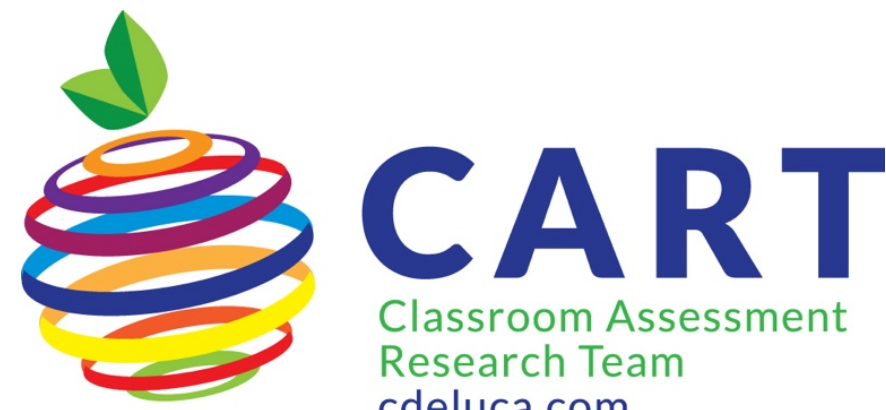

Classroom Assessment

Contact:

Research Team

cdeluca.com

Christopher DeLuca

cdeluca@queensu.ca

@ChrisDeLuca20 


\begin{abstract}
Conceptualizing fairness through social psychology theory has recently been called for in classroom assessment (CA) literature. This study used two open-ended questionnaires to explore university students' critical incidents of fairness and unfairness and their affective and behavioral reactions to experiences of un/fairness. The findings showed that students' perceptions of CA fairness were comprised of distributive, procedural, and interactional justice principles. Collectively, students considered the distribution of outcomes, the procedures for outcome distributions, the interpersonal relationships, and the communication procedures in conceptualizing fairness. Students also reported positive feelings such as happiness, satisfaction, feeling valued, and hopefulness when describing fair incidents, while they tended to report negative feelings such as anger, upset, disappointment, and embarrassment as responses to unfair incidents. Students also reported increased classroom engagement and greater adaptation in responses to fairness incidents, while they reported class disengagement, inaction, and dissent as responses to unfair incidents. Building on these empirical findings, a more comprehensive conceptualization of fairness in CA contexts is proposed.
\end{abstract}

Keyword: Fairness, Classroom assessment, Social psychology of justice, Iranian students, University 


\section{Introduction}

Fairness is at the heart of students' experiences of education and assessment (Mazzoli Smith, Todd, and Laing, 2018; Tierney, 2013). Studies have shown that students' perception of classroom fairness is linked to their level of academic achievement (Holmgren and Bolkan, 2014), engagement (Berti, Molinari, and Speltini, 2010), and motivation for learning (Chory-Assad, 2002). In contrast, perception of classroom unfairness is associated with student truancy (Ishak and Fin, 2013), cheating (Murdock, Miller, and Goetzinger, 2007), and negative behaviors (e.g., hostility and aggression) (Chory-Assad and Paulsel, 2004b; Chory-Assad and Paulsel, 2004a). Despite these strong empirical relationships, fairness remains an ambiguously understood construct within assessment literature, with varying conceptions and definitions often predicated on a psychometric logic (Tierney, 2013). Researchers have called for conceptualizing fairness specially for classroom contexts to contribute toward 'classroometric' (Brookhart, 2003) theories of assessment (Rasooli, Zandi, and DeLuca, 2018; Tierney, 2013, 2014). To address these calls, the purpose of this study is to provide an initial empirical foundation for a conceptualization of fairness rooted in Iranian students' classroom experiences.

Researchers have recently defined and conceptualized fairness in classroom assessment (CA) contexts using a social psychology theory of justice, arguing that this theory can account for fairness conceptions of all students (Grace, 2017; Rasooli, Zandi, and DeLuca, 2019). This conceptualization is typically characterized by three main questions: (a) what are the antecedents of students' un/fairness perception?; (b) how do students shape their un/fairness perception?; and (c) what psychological and social consequences proceed from students' un/fairness perception? (Rasooli et al., 2019; Resh and Sabbagh, 2016). Underpinning these questions are core principles related to three dimensions of social psychology of justice (i.e., distributive justice, procedural justice, and interactional justice) that also bring about affective and behavioral reactions for students. Distributive justice looks at the fairness of outcome distributions; procedural justice examines the fairness of 
procedures for outcome distributions; and interactional justice considers the fairness of interpersonal behavior and communication of information. Collectively, these three dimensions shape students' perception of un/fairness that subsequently lead to students' positive and negative affective and behavioral reactions.

The purpose of this study is to further extend social psychology theory of justice into CA literature to conceptualize a fairness theory for CA contexts. Specifically, this study aims to explore Iranian students' conceptualizations and critical incidents of CA fairness through a social psychology theory to provide an initial empirical foundation for a multidimensional conceptualization of CA fairness (Rasooli et al., 2019). This study is guided by the following research questions:

1. What justice principles are evident in students' articulated critical incidents and conceptualizations of fairness within CA contexts?

2. What affective and behavioral consequences do students experience in relation to fair and unfair incidents within CA contexts?

\section{Social Psychology of Justice Research in Education}

Conceptualizing fairness through a social psychology theory of justice began in organizational, political, and legal contexts, where researchers attempted to identify how individuals understood fairness in the workplace and in courtrooms with attention to their psychological, social, and cognitive reactions to fairness (Greenberg, 1987; Kazemi, Törnblom, and Mikula, 2015; Thibaut and Walker, 1975). A social psychology approach to fairness consists of three dimensions: distributive justice, procedural justice, and interactional justice. Distributive justice refers to the distribution of outcomes based on the principles of equity (i.e., comparison of the ratio of contributions to the outcomes of an individual with that of a similar individual), equality (i.e., distribution of outcomes equally among individuals), and need (i.e., distribution of outcomes based on individuals' needs). Procedural justice refers to the fairness of procedures for outcome distributions through principles of consistency (i.e., consistent implementation of a procedures), bias 
suppression (i.e., neutral implementation of procedures), accuracy (i.e., accurate implementation of procedures), correctability (correction of procedures if identified as implemented wrongly), voice (i.e., consideration of students' concerns during the implementation of procedures), and ethicality (i.e., ethically-aligned application of procedures). Finally, interactional justice includes fairness of interpersonal interactions and communications through principles of respect (i.e., respectful interpersonal relationship), propriety (i.e., respectful communication of information) truthfulness (i.e., honest communication of information), and justification (i.e., logical explanation of outcomes and procedures) (Adams, 1965; Bies and Moag, 1986; Deutsch, 1975; Greenberg, 1993; Leventhal, 1980; Thibaut and Walker, 1975).

Drawing on this conceptualization, educational and assessment scholars have begun to apply this theory to classroom contexts to understand students' perceptions of fairness (Cronen and Fuller, 1976; Oppenheimer, 1989; Rodabaugh, 1994; Thorkildsen, 1993). As indicated by a recent systematic review of the fairness in educational and assessment literature (Rasooli et al., 2018), most of the quantitative studies focusing on the social psychology theory of justice in classroom contexts have heavily drawn on the principles of distributive, procedural, and interactional justice fostered originally within workplace and legal contexts (e.g. Chory-Assad, 2002; Holmgren and Bolkan, 2014). While there is some evidence to show the prevalence of these principles across legal, organizational, and health contexts (Colquitt, 2001; Siegrist, 2015), theoretical studies have argued the need to empirically and qualitatively explore fairness using these principles in instructional and assessment contexts (Grace, 2017; Kazemi, 2016; Rasooli et al., 2019; Resh and Sabbagh, 2016; Sabbagh and Resh, 2016).

Compared to quantitative studies, we identified and reviewed 9 qualitative studies that attempted to develop a conceptualization of social psychology of justice apt for classroom contexts. Israelashvili (1997) interviewed 233 school students in Israel, and Čiuladienė and Račelytė (2016) explored 99 university students in Lithuania to identify experiences of unfairness. These authors 
reported that their participants experienced unfairness in relation to punishment, abusive and aggressive mistreatment, unbalanced and partial behavior, grading system and examinations, and teacher defensiveness.

Houston and Bettencourt (1999) and Robbins and Jeffords (2009) administered open-ended questionnaires to explore university students' perception of instructor un/fairness in the US. They found similar categories in relation to students' un/fairness perception: (a) equal and respectful interpersonal interactions or lack thereof; (b) consistent, but flexible in special cases, application of classroom procedures or lack thereof; (c) assignment of course grades based on deservedness, knowledge of material, and efforts or lack thereof; (d) un/timely and un/clear communication of expectations; and (e) in/congruence of course and content exam.

The remaining studies used open-ended surveys and focus group interviews to explore students' experiences of unfairness in the US and Russia (Bempechat, Ronfard, Mirny, Li, and Holloway, 2013; Buttner, 2004; Chory, Horan, and Houser, 2017; Horan, Chory, and Goodboy, 2010; Lizzio and Wilson, 2008). These studies identified similar themes in relation to distributive, procedural, and interactional justice dimensions, and were valuable because three of them also explored students' affective and behavioral reactions to unfair conditions (Buttner, 2004; Chory et al., 2017; Horan et al., 2010). These three studies demonstrated that teachers' unfair behavior led students to feel angry, pained, frustrated, powerless, stressed, violated, cheated, embarrassed, empathetic, and disgusted. Moreover, students also reported to show behavioral reactions of dissent, inaction, hostility, withdrawal from the course and classroom participation, and adaptation (i.e., putting more effort to compensate injustice). In the last two, Bempechat et al. (2013) found an additional dimension of instructional justice, including themes like ineffective teaching affects grades and teacher unprofessionalism in communicating the content well and managing the classroom discipline. Finally, Lizzio and Wilson (2008) found fairness to be a dimension of effective 
assessment feedback. Fairness of feedback included issues such as justification of grades, transparency in communications, and provision of voice.

Analyzing the findings across these studies, we noticed that most have conflated justice principles with domains in their thematic analyses. Previous studies have identified, for example grades, examinations, feedback, and punishments as themes related to distributive, procedural, and interactional justice principles (e.g., Horan et al., 2010; Houston and Bettencourt, 1999). These themes may be best identified as domains where students apply distributive, procedural, and interactional justice principles (e.g., equity, equality, respect, and accuracy as outlined earlier) to arrive at perception of fairness. For example, if feedback is identified as a theme leading to an unfairness perception, it would be hard to argue whether unfairness of feedback resulted from the bias suppression principle (i.e., the feedback was sex-biased) or the respect principle (i.e., the feedback was disrespectful). Therefore, there is a need for qualitative studies to identify justice principles in the data and then map the principles to students' experiences of fairness in particular domains. Such an analysis would not only help detect justice principles more relevant to educational and assessment contexts but also identify possibilities of additional principles operating discretely within classroom contexts.

\section{Method}

A critical incident technique (CIT) was employed to explore Iranian students' incidents of fairness within their higher education classroom contexts. CIT is most appropriate when individuals are asked to report retrospectively from memory about salient incidents that happened in the past (Butterfield, Borgen, Amundson, and Maglio, 2005). For this study, CIT serves well to investigate incidents of un/fairness because previous qualitative studies focusing on students' fairness experiences (Alm and Colnerud, 2015; Buttner, 2004; Chory et al., 2017; Čiuladienė and Račelytė, 2016; Horan et al., 2010; Houston and Bettencourt, 1999) demonstrated that un/fairness incidents were particularly salient in students' memories, able to be recalled years later. 
CIT can be conducted through interviews and questionnaires (Kemppainen, 2000). In this study, we garnered data through two open-ended questionnaires because they not only provided an in-depth understanding of students' fairness incidents, but also systematically captured the diverse range of incidents and their associated affective and behavioral reactions.

\subsection{Data Collection}

Participants were recruited from a university in Iran through a purposeful sampling strategy. A purposeful sampling strategy is used when the researcher selects participants who serve a particular purpose in relation to the research question and can provide a rich understanding of a phenomenon (Creswell, 2007). To recruit students, three researchers provided information about the study to students whilst on-campus between classes. Once the study purpose and design was explained to the participants and their questions were answered, verbal consent was obtained from each participant. Participants were then provided with either the fairness or unfairness questionnaire based on their recollection of either a fair or an unfair incident. Collectively, the two questionnaires included six open-ended questions to elicit students' critical incidents of un/fairness during higher education. Inspired by previous studies (Horan et al., 2010; Houston and Bettencourt, 1999), the first question for both questionnaires asked students to describe a time when a teacher did or said something they perceived un/fair (i.e., write a narrative of an un/fair incident). The second question asked participants to describe how they felt after this un/fair behavior. The third question asked what reactions the participants had in response to their teachers' un/fair behavior.

There were no limits placed on participants' responses. Some students provided detailed accounts of their un/fairness incident(s), while some provided more concise answers. The questions were intentionally crafted to focus beyond assessment incidents, as previous literature has conceptualized CA fairness in relation to classroom elements of teaching, learning, and classroom interactions demonstrating the interplay between assessment fairness and these other classroom 
elements (Rasooli et al., 2018; Tierney, 2016). As expected, the majority of un/fair incidents dealt with experiences related to assessment (i.e., 66\%; 392 of 592 incidents).

In total, 502 participants responded, with 199 selecting the fairness questionnaire (i.e., sharing an experience of classroom fairness) and 303 selecting the unfairness questionnaire (i.e., sharing an experience of classroom unfairness). Forty-eight percent of participants were male and 51\% female, with a mean age of 22 years. Participants were from diverse educational levels $(34.7 \%$ bachelor, 20.1\% masters, 5.4\% $\mathrm{PhD}$, and 39.8\% did not answer) and faculties (12.2\% Engineering, $4.2 \%$ Arts, 11.2\% Humanities, 7.8\% Basic sciences, 25.1\% Language Arts, 39.5\% did not answer).

Additional demographic data were collected related to the sex and university rank of the un/fair teachers in the incidents. Analysis showed that participants recollected unfairness incidents from male teachers $(76.8 \%)$ compared to female ones (18\%, $5.2 \%$ declined to indicate sex). Unfairness incidents were also more associated with assistant professors (42.8\%), followed by associate $(20.6 \%)$, full $(20.3 \%)$, and adjunct professors $(5.9 \%, 10.4 \%$ declined to indicate teacher rank). In reporting on fairness incidents, students reported more fair incidents with male teachers (73\%) than female teachers $(17 \%, 10 \%$ declined to answer), and with assistant professors $(34.5 \%)$, compared with full (27\%), associate (16\%), or adjunct professors $(7.5 \%, 15 \%$ declined to answer). More un/fairness incidents from male teachers vis-à-vis female teachers might result from the lower ratio of female teachers (16.2\%) to male teachers (83.8\%) across all Iranian universities (Seifi, 2017). Further, more un/fairness incidents from assistant professors may be because $79 \%$ of teachers in Iranian universities have an assistant rank (Seifi, 2017) and most undergraduates are taught by assistant professors.

\subsection{Data Analysis}

All data from the questionnaires were thematically analyzed to identify the justice principles, the domains, and the affective and behavioral reactions. To identify the justice principles, an initial code list was deductively constructed based on the previous literature that included principles related 
to each dimension of justice: distributive, procedural, and interactional justice. Distributive justice principles (i.e., equality, equity, and need) were benchmarks based on which students judged the un/fairness of outcome distributions. Procedural justice principles (i.e., accuracy, consistency, bias suppression, correctability, ethicality, voice, transparency, and reasonableness) were benchmarks whereby students judged the un/fairness of procedures for outcome distributions. Interactional justice principles (respect, caring, adequate, truthful, and justified information, and timeliness) were benchmarks according to which students judged the un/fairness of interpersonal behavior and communication of information (Colquitt, 2001; Greenberg, 2011; Rasooli et al., 2019).

Drawing on this code list, three researchers proficient in Persian and English read and re-read the incidents and coded the distributive, procedural, and interactional justice principle(s). In addition to coding the principles, domains (i.e. areas such as grading, feedback, and punishment) in which students experienced un/fairness were also coded. This code list along with representative examples from the data were translated into English to discuss it with the additional researcher proficient only in English. This researcher's reflections provided additional revisions on the codes and helped to further refine the analysis. As an illustration of how justice principles and domains were coded, let's examine the following incident. One of the students composed the following response regarding his incident of unfairness: the teacher has asked for a load of difficult homework that must be done just within a week. This response was coded as containing the procedural justice principle of reasonableness (i.e., meaningful and logical implementation of classroom procedures) in the domain of workload. The codes for each justice principle along with the associated domain were tallied in the incidents to calculate the frequency. The frequencies represent the number of justice principles that students used in their description of critical incidents to describe their un/fairness perception in a particular domain. These frequencies are thus an aggregate of each justice principle in a particular domain across all un/fairness incidents as articulated by students. Tables 1, 2, and 3 present distributive, procedural, and interactional justice principles, their associated domains, and the 
frequencies. The frequencies in the Tables also characterize the relative weighting of each principle of the fairness framework on students' experiences of un/fairness.

The affective and behavioral questions were inductively analyzed to identify the affective and behavioral reactions that students had in response to un/fairness situations. Three researchers read the affective and behavioral reaction questions several times and coded them individually. They then met to discuss the codes until the disagreements were settled. The codes with representative examples were then translated into English for additional feedback from the English-speaking researcher. This researcher further helped fine-tune the codes. As an illustration on how coding was done for affective and behavioral reactions, the same student responded: felt anger, as an answer for the affective reaction question, and nothing could have been done; otherwise our grades were at stake, as an answer for the behavioral reaction question. The affective response was coded as negative attitude toward the teacher (i.e., anger) and the behavioral one coded as inaction. These affective and behavioral reactions were tallied across un/fairness data to determine the frequency of each. Table 4 and 5 present codes related to students' affective and behavioral reactions in the un/fairness situations. Overall, the analyses helped answer the research questions by encompassing the justice principles that students drew on to perceive un/fairness in classroom contexts and the affective and behavioral reactions they showed to un/fairness.

\section{Findings}

In this section, we present the distributive, procedural, and interactional justice principles, related domains, and students' affective and behavioral reactions.

\section{INSERT TABLE 1 HERE \\ INSERT TABLE 2 HERE \\ INSERT TABLE 3 HERE}

Overall, across fairness and unfairness data, two principles of equality and equity were found in reference to distributive justice; seven principles of consistency, reasonableness, bias suppression, transparency, voice, correctability, and ethicality were found in relation to procedural justice; and four principles of respect, caring, adequate, truthful, and justified information, and timeliness were 
identified with respect to interactional justice. As related to the affective responses to fair incidents, themes of positive attitude toward the teacher, feeling valued, and hopeful were found. In contrast, themes of negative attitude toward the teacher and the university system, disappointed, embarrassed, and stressed were identified as affective responses to unfair incidents. Finally, two themes of engagement and adaptation were found for behavioral reactions to fair incidents, while themes of inaction, dissent, and disengagement were reported as behavioral responses for unfair incidents.

\subsection{Distributive Justice Principles}

Equality and equity of outcomes were the primary principles that emerged in relation to distributive justice incidents in the classroom $(n=173)$. These two principles were salient mainly in relation to student opportunity to participate in the classroom, teacher affect and attention toward students as well as teacher grading practices (See Table 1). With respect to the equality principle, students described 41 fair incidents when teachers distributed classroom participation opportunities as well as affect and attention equally: "the teacher provided everyone with equal opportunity to take part in classroom discussions" (Humanities student); "the teacher had eye contact with everyone" (Humanities student). Likewise, six unfair incidents were associated with classroom participation opportunities, and teacher affect and attention: "the teacher gave more opportunities to some students to participate and talk" (Languages student); "the teacher's behavior was different across students; he paid more attention to a few students" (Basic Sciences student).

With respect to the equity principle, students reported 47 fair incidents when they received grades and feedback that valued and matched with the amount of contributions they made. Within the grade distribution, students reported fair incidents when their effort, progress, and ability were counted in their grades: "“"the international law instructor gave fair grades to all by considering students' performances" (Humanities student), and 
I put a lot of effort into the classroom project and did a good work, but I had a bad presentation of the project within the classroom. The teacher did not take my effort for granted and considered it in my grade (Engineering student).

With respect to the distribution of feedback, students described fair incidents when they received the feedback they deserved: "the teacher was acting similarly across students' presentations and each student got positive and negative comments depending on the quality of their work" (Engineering student).

Students reported 79 unfair incidents when they received grades and punishments that were not comparable to the contributions they made. With respect to grades, students reported unfairness when teachers took into account factors such as appearance, student behavior, and grade drop due to grade appeal: "one of the teachers dropped my grade for 4 credits/points due to my clothing style" (Languages student); "after my appeal for the grade through an email, the teacher replied with a harsh tone that also affected my grade negatively" (Humanities student). Moreover, students reported unfairness when they got lower grades while their contribution (e.g. effort and work quality) was similar to other classmates: "it was really vexing that I spent a lot of time doing a project, but others who copied from other sources got higher grades" (Engineering student); "although I have worked equally compared to other members in the group, my grade was 3 grades lower" (Basic Sciences student). In relation to distribution of punishments, students described unfair incidents when they received punishments that they did not deserve: "one of the students said something that teacher thought it was me, and then he began to criticize me" (Basic Sciences student).

In total, the data suggest that equality and equity principles play significant roles in students' understandings of fairness in relation to distribution of assessment opportunities, grading practices, classroom participation opportunities, feedback, and punishments.

\subsection{Procedural Justice Principles}


Seven principles were identified in relation to procedural justice incidents: consistency, reasonableness, bias suppression, transparency, voice, correctability, and ethicality $(n=184)$. These principles were mainly salient in relation to assessment practices, assignment, classroom attendance, syllabus, as well as pedagogical and scheduling practices (See Table 2). Students invoked fair incidents $(\mathrm{n}=16)$ when a teacher maintained promises and performed consistently in relation to four domains of assessment, scheduling, attendance policy, and syllabus. "A teacher detailed his expectations, syllabus, and grading criteria and kept the same expectations at the end of the course" (Basic Sciences student); "the teacher took an exam aligned with the content he had already taught" (Arts student). Students also invoked unfairness incidents when a teacher failed to maintain promises related to assessment, scheduling, attendance policy, and syllabus domains ( $\mathrm{n}=29)$. "On the Dynamics exam, the teacher told us that if we get the equation right, we will get the grade, but after the exam, he denied saying such a thing and dropped our grades" (Engineering student); "the teacher set a deadline for handing in the assignment and warned of a grade drop for late submission. I submitted mine in its due time, but I got to know that a student submitted two months later and got the grade" (Humanities student); "I was absent for some sessions due to preparation for the Masters Entrance Exam, and the teacher told me to drop the course, while my absences were less than number of absences permitted by the university policy" (Basic Sciences student).

Students expressed 17 fair incidents when teachers' assignments and pedagogy were reasonable and meaningful: "the fair teacher gave reasonable workload based on our busy schedule" (Engineering student); "the English teacher treated us who were theatre students fairly in two aspects. First, her expectation of each student was based on their English ability. Second, she taught us in relation to theatre field and used visual arts techniques" (Arts student). Forty-one unfair incidents were articulated when students believed that teacher assignment, attendance policy, pedagogy, assessment, and course content were not meaningful and logical. "The teacher has asked for a load of difficult assignments that should be done just within a week" (Humanities student); "a teacher 
dropped students' grades for one grade for being late even for one minute. This is totally unfair" (Basic Sciences student); "we have just started learning a foreign language, so it is really unfair that the teacher taught and assessed us in an advanced level" (Languages student); "a teacher gave a very unfair test from a 500-page book in a way that the test assessed very detailed information, hard to remember" (Humanities student); "the course content that the teacher introduced was beyond our abilities" (Humanities student).

Students articulated 20 fair incidents when their teachers' assessment and grading practices were not sex-biased and influenced by a priori impression: "our teacher removes the student names from the exam papers to avoid being affected by students' personal characteristics" (Engineering student). In contrast, students reported 21 unfair incidents when teachers' assessment and grading practices and punishments were sex-biased or informed by previous impressions: "sex discrimination in our faculty is widespread and female students usually get higher grades" (Male Engineering student); "the topics, discussed in the classroom, were so masculine that female students could not participate effectively and their grades were affected negatively" (Female Languages student); “the teacher gave grades based on his previous impressions and background of students in previous terms" (Basic Sciences student). “the teacher's favorite student disrupted the classroom discipline, but the teacher blamed another student for the disruption and threw him out of the class despite that the favorite student told he disrupted" (Languages, Third Party Observant).

Transparency was another dominant principle that students drew on to describe their un/fairness incidents $(n=16)$ when the teachers enacted assessment and grading practices clearly or opaquely: "the teacher had detailed and clear grading criteria and gave grades based on deservedness" (Languages student), and

In one of my courses, one of the noted teachers of the university gave no clear feedback and explanation when judging my work and he always realized my work as low quality. The entire term I was wondering what work is actually good (Arts student). 
Students also described 11 fair incidents when they were provided with voice to articulate their opinions about teacher grading, scheduling and syllabus; "the teacher consulted students on the syllabus to reach an agreement on a useful and adequate syllabus for the entire course" (Languages student); "the fair teacher let us decide the date of the exam for Mathematics Analysis course" (Basic Sciences student); "after grading the exam papers, the teachers allowed us to look at the exam papers and appeal for our grades (Basic Sciences student). Two unfair incidents were recounted when students were deprived of voice to participate in the classroom and articulate their opinions on a teacher's scheduling decision: "the teacher was articulating his opinion on an issue with which I was in disagreement based on my prior readings. Once I wanted to articulate my opinion, the teacher stopped me, arguing that there was not enough time" (Languages student); "the teacher was deciding the time to hold the make-up classes and he just considered his own timetable without consulting students" (Humanities student).

Students reported eight fair incidents when their teachers corrected their wrong decisions in relation to assessment, feedback, and pedagogy practices; "the teacher did not instruct a chapter, but gave questions from that chapter on the exam. After telling her, she accepted and removed those questions" (Engineering student); "the teacher had a harsh behavior against a student who was talking in the class and changed his/her seat. After five minutes, the teacher apologized for his behavior" (Engineering, Third Party Observant); "there was a topic that the teacher had explained wrongly in the classroom. I counter-argued but the teacher did not take it. Next session, he said he was wrong and I was right” (Basic Sciences student).

Finally, students described three unfair incidents when their teachers' grading and anticheating practices did not align with the academic ethical guidelines: "the teacher considered research and presentation as his criteria for grading, but as he needed published manuscripts for promotion, he told that a failure to submit papers would make our grades in the borderline" (Basic Sciences student); "students were cheating on the exam but the teacher ignored and did not give 
warnings. Students who did not cheat were failed or received a very low score" (Engineering student).

In total, the findings show that students apply principles of consistency, reasonableness, bias suppression, transparency, voice, correctabiliy, and ethicality to understand the un/fairness mainly in relation to teachers' assessment, pedagogical, and managerial practices.

\subsection{Interactional Justice Principles}

Four principles emerged in relation to interactional justice incidents: respect, caring, adequate, truthful, and justified information, and timeliness $(n=235)$. These principles were salient mainly in relation to classroom interpersonal relationships, teacher feedback and scheduling practices, as well as teacher assessment and pedagogical practices (See Table 3). Students described 24 fair incidents when their teachers had respectful interpersonal relationships, provided instructive feedback (i.e., content-related feedback) respectfully, and reacted against peer bias. "The teacher did not discriminate among students based on their gender and appearance" (Humanities student); "the teacher answered students' questions with respect and decorum" (Humanities student); "some of the friends started to mock a classmate because s/he was using a common method to solve a problem, but the teacher reacted and prevented them from embarrassing the student" (Basic Sciences, Third Party Observant). Students invoked 102 unfair incidents when teachers had disrespectful interpersonal relationships, provided instructive feedback and general feedback (feedback on grades, student behavior, and general classroom procedures) disrespectfully, and punished with disrespect. "A student voiced a criticism and the teacher began to belittle the student instead of accepting his fault" (Basic Sciences, Third Party Observant); "a teacher gave an assignment that I failed to do. He embarrassed me in front of my classmates" (Languages student); "we were in the class where a student talked to a classmate next to him, the teacher immediately got angry and began to insult him" (Engineering, Third Party Observant); “some teachers behaved differently toward female and male students. They had negative behavior towards female students" (Humanities student); "in the Islamic 
sciences course, the teacher advocated Shia branch of Islam and challenged the Sunni branch. Though I am a Shia, I got upset to see an international student, who was Sunni, leave the classroom" (Humanities, Third Party Observant); "I had to text with my cellphone as it was necessary, the teacher saw and threw the marker at me and angrily [tone of language] said anyone who does not want to listen, should go out" (Engineering student).

Students described 12 fair incidents when their teachers took into account caringly their special circumstances when deciding exam schedules, grading, and punishments for cheating. "The teacher was supposed to give a mid-term exam, but on the exam day I had an accident and could not be present in the class. After showing my accident documents, the teacher gave me another test" (Humanities student); “the teacher's grading was based on students' classroom activities and exam results, but if a student had had an emergency and could not have taken part in the exam, the teacher solely based his grades on the classroom activities" (Arts student); "after catching my cheating on the mid-term exam, the teacher did not give my final 0.25 (out of 20) and just gave me zero on the midterm exam" (Engineering student). Seven unfair incidents were typically associated with teachers' uncaring decisions in relation to exam schedules, assessment, and attendance policy. "The teacher did not take students' circumstances into account when setting a date for the mid-term exam, while we also had exams for other classes (Engineering student); "in the physical education exam, I told the teacher that I couldn't run due to my health condition, but he forced me to run, leading me to feel bad and vomit (Engineering student); "a student were absent for 4 sessions due to the leg break and had approved documents from a doctor to be absent for 3 sessions. Despite submitting the documents, the teacher made the student drop the course" (Arts, Third Party Observant).

Students reported 29 fair incidents when their teachers not only communicated the grades, content-related feedback, and pedagogical instructions sufficiently, honestly, and logically, but also considered students' opinions on these issues seriously. "One of the students appealed his/her grade and the instructor brought the exam paper and attended logically to the student's grade appeal" 
(Humanities, Third Party Observant); "the teacher listened carefully to my presentation. He stated the shortcomings and strengths of the work in a way that made me motivated to finish my work" (Engineering student); "In the topic of diverse types of literature from Aristotle's point of view, the teacher listened to diverse opinions and discussed all of them" (Humanities student). Students articulated 59 unfairness incidents when their teachers not only communicated content-related feedback, grades, and pedagogical instructions inadequately, wrongly, and illogically, but also did not take into account students' opinions. "The teacher asked me to read a text from an ancient language and I read it with a proper pronunciation, but he argued that my pronunciation of several words was incorrect without providing any scientific or reasoned justification" (Humanities student); "I dissented to the teacher why I got 15 (out of 20) on the exam, while I had given complete answers to all the questions. He said that others' exam papers had more lengthy answers" (Arts student); "the English grammar teacher avoided explaining the grammar section again and told us that he is only required to explain it once" (Languages student); "The most unfair behavior in the classroom was that teachers digressed from course content and got involved in telling memories and stories" (Humanities student).

Finally, students perceived unfairness in two incidents where their teachers failed to communicate the grades timely: "another unfairness is that it is one month that the teacher has not communicated the grades" (Languages student).

Collectively, students' perception of interactional justice included the way teachers behaved, gave feedback, enacted assessments and pedagogical instructions, and considered students' special circumstances respectfully and caringly as well as the way their teachers presented feedback, grades, and pedagogical instructions adequately, truthfully, logically, and timely.

\subsection{Affective and Behavioral Reactions}


Three themes emerged related to students' affective responses to fair incidents: positive attitude toward the teacher, feeling valued, and hopeful $(n=143)$. Positive attitude toward the teacher was the most salient emotional response to a teacher's fair behavior (See Table 4). Within this theme, students reported happiness, satisfaction, respect, good feeling, trust, and liking of their teachers. "My classmates and I felt satisfied and happy about the teacher's behavior" (Humanities student). "I always remember him with good feelings" (Arts student). "I got sure of the instructor's fairness and hence I was more satisfied with evaluation of the course and my grades” (Humanities student). “As he spent time and crafted questions for my missed exam, I respected him since then. I always remember his goodness" (Basic Sciences student). "I really liked the instructor being just and fair" (Engineering student). With respect to feeling valued and hopeful, students reported that, "we felt that the teacher valued students' status and personalities" (Languages student); "I felt that there are still teachers who are fair" (Humanities student); "I felt hopeful about the future of my education" (Engineering student).

Four themes were also identified in relation to students' affective responses to unfair incidents: negative attitude toward the teacher and university system, disappointment, embarrassment, and stress $(n=266)$. Negative attitude toward the teacher and university system was the most salient emotional response to a teacher's unfair practice, followed by disappointment and embarrassment (See Table 4). Within the theme of negative attitude toward the teacher and university system, students reported upset, anger, dislike, distrust, bad feeling, and disgust. "I got upset and demotivated" (Basic Sciences student); "I felt extremely angry that there are such teachers at this university" (Humanities student); "I cried and disliked the teacher" (Basic Sciences student); "I no longer believed in what the teacher says" (Basic Sciences student); "I had a very bad feeling because the teachers gave higher grades to favorite students" (Humanities student); "I hated the teacher" (Engineering student). Regarding the feelings of disappointment, embarrassment, and stress, students 
expressed, "I got disappointed as I did not expect him to behave like that" (Arts student); "I got really embarrassed in front of other students (Engineering student)"; "I got stressed" (Languages student).

Two themes of engagement and adaptation emerged related to students' behavioral responses to fair incidents $(\mathrm{n}=155)$. The theme of engagement was reported by students twice as much as the adaptation theme in response to fair teacher practice (See Table 5). Within the theme of engagement, students reported more interest in learning and classroom participation as well as enhancement of their confidence and motivation: "I had a more interest in studying the course and had an increasing motivation for success and progress" (Languages student); "I got more self-confidence in the class" (Humanities student); "I got motivated to try more as I was confident that if I try more, I will get better results" (Engineering student). With respect to adaptation, students reported that they tried to adapt their teachers' fair behavior into their own life and promised to be a fair individual. "My instructor's fair behavior has always been in my memory and I tried to behave like him in family relations and friendships" (Humanities student); "if I become a teacher or find another job, I would put fairness and justice on my priority" (Basic Sciences student).

Three themes of inaction, dissent, disengagement were identified as students' behavioral responses to unfair incidents $(\mathrm{n}=324)$. Themes of inaction and dissent were reported more often by students in response to unfair teacher practice (See Table 5). Within inaction theme, students oftentimes stated that they stayed silent and did nothing due to their teachers' great power, failure of dissents to have any effects, expediency to avoid getting into troubles in their grades and future courses with the same teacher, and lack of a constructive environment to voice their dissents. "I did nothing specific as it does not have any effects" (Humanities student); "I did nothing as the dissent with respect to the high status of the teacher would get me in trouble" (Basic Sciences student); "dissent to a teacher in terms of the grade induces the teacher's reaction in the following courses and worsens his bad impressions of me" (Humanities student); "the classroom environment was not friendly that I could talk about my feelings" (Arts student). 
Students showed their dissents through disagreeing with a teacher individually, collectively, and via an email, talking to a superior such as a university principal, talking with the classmates and friends, and leaving the class: "I not only dissented to him personally but also through an email, but it did not have any effect" (Humanities student); "We also informed the graduate studies, but did not have any result" (Engineering student); "I talked to classmates and friends about that topic but it did not change anything" (Basic Sciences student); "as he checked my absence, I left the class" (Arts student).

With respect to disengagement, students maintained that they got demotivated, decided to quit the program, withdrew from taking any additional courses with the unfair teacher, stopped being in touch with the teacher, and lost focus, self-confidence, and interest in the classroom. "I felt demotivated and became indifferent about his course" (Humanities student). "I kept silent and withdrew from asking any question in his class" (Engineering student). "I stopped taking any additional courses with that teacher" (Humanities student). "His behavior was so disrespectful that I decided to drop the course" (Engineering student).

\section{Discussion}

Given the emphasis on fairness as a critical aspect of CA contexts (Rasooli et al., 2018; Tierney, 2013), researchers have begun to conceptualize CA fairness predicated on theories beyond assessment and measurement arenas (Rasooli et al., 2018; Tierney, 2014). In response to these calls, several researchers have built on social psychology theories to conceptualize fairness for CA contexts and called for empirical studies across contexts to move this conceptualization forward (Grace, 2017; Rasooli et al., 2019). This study presents preliminary empirical evidence on this conceptualization by offering a more comprehensive understanding of CA fairness embedded within the university context.

Findings from our study suggest that students' conceptualization of CA fairness consists of three dimensions: distributive justice, procedural justice, and interactional justice. Within each of 
these dimensions, we identified justice principles that contributed to students' perception of fairness. Regarding distributive justice, previous theoretical conceptualizations in CA, organizational, and legal contexts (Greenberg, 2011; Kazemi and Tornbolm, 2008; Rasooli et al., 2019) have identified three principles of equity, equality, and need. Consistent with this literature, we found that students used two principles of equality and equity to perceive fairness in relation to assessment opportunities as well as grading and feedback practices. However, contrary to the previous literature, we did not identify incidents where students drew on the need principle to judge fairness. This finding may result from the significance of equity and equality principles relative to the need principle in shaping Iranian students' critical incidents of CA fairness in this university context. More empirical research is needed to understand how these distributive justice principles operate across diverse CA contexts.

In relation to procedural justice, previous conceptualization of fairness organizations (Kazemi and Tornbolm, 2008; Leventhal, 1980) identified principles of accuracy, consistency, bias suppression, voice, correctability, and ethicality. Two principles of reasonableness and transparency were also added to this conceptualization by the previous CA fairness conception (Rasooli et al., 2019). Except for the accuracy principle, we identified the remaining principles with their particular meanings in CA contexts. When analyzing the data, we could not understand how accuracy, for example, in grading practices was different from equity principle in students' interpretations. Students in this study particularly interpreted consistency in terms of teachers' promise-keeping in the congruent enactment of assessments and syllabi. Our results also empirically supported reasonableness and transparency as two principles operating discreetly within CA contexts. The remaining four principles - bias suppression, voice, correctability, and ethicality - appear to be shaping students' perception of fairness in the major areas of assessment, grading, feedback, and pedagogy. Particularly, students in this study interpreted ethicality as teachers' adherence to academic guidelines in relation to grade construction and supervisions of students' cheating on the 
exams. We call for additional empirical evidence to examine the prevalence of these procedural principles across diverse CA contexts.

With respect to interactional justice, previous literature of fairness in organizations (Bies and Moag, 1986; Colquitt, 2001; Siegrist, 2015) identified principles of respect, adequate, truthful, and justified information. The two principles of caring and timeliness were also added to the CA fairness conceptualizations (Rasooli et al., 2019). We identified these principles in our data with their particular value for classroom contexts. Students in this study interpreted respect not only in relation to general interpersonal relationships, but also in terms of respectful communication of instructive feedback and grades. Our findings empirically supported caring and timeliness as the principles contributing to students' conceptualization of fairness for CA contexts. The students also invoked adequate, truthful, and justified information principle to understand fairness not only in relation to how teachers communicate the proactive information, feedback, and grades, but also the way teachers listened to and considered students' opinions.

Our findings in relation to affective consequences demonstrated that students show positive and negative reactions in response to un/fair incidents. Students in this study reported positive feelings and attitudes toward a teacher in fairness incidents, while they reported negative feelings and attitudes in unfair incidents. These affective responses, which resulted from teacher un/fairness, were also found in previous research (Horan et al., 2010), suggesting that teacher unfairness can provoke acute emotions that can subsequently affect students' cognitive and affective learning. In this respect, Vogl and Pekrun (2016) have highlighted the key role of students' emotions in the effective enactment of CA processes, with additional research needed to investigate the role of CA practices on students' emotions and their influence on students' motivation, learning, and well-being. Drawing on the results of this study, we noticed that perception of CA fairness influenced students' emotions and affective classroom-related outcomes such as learning, motivation, and well-being. We believe that 
more research is needed to map the intersection of social psychology of justice, emotions, and CA practices.

Students also reported behavioral reactions to un/fairness incidents. Students reported engagement and adaptation in fairness incidents, while they demonstrated disengagement, inaction, and dissent in cases of unfairness. These findings resonate with previous empirical studies, demonstrating that students' fairness perceptions have a positive relationship with their motivation for learning (Chory-Assad, 2002; Kazemi, 2016) and psychological and social engagement with teachers and educational institutions (Berti et al., 2010; Resh and Sabbagh, 2014), and negative relationships with students' aggression and hostility (Chory-Assad and Paulsel, 2004a). This evidence, coupled with findings of this study and previous studies (Chory et al., 2017; Horan et al., 2010; Robins and Jeffords, 2009), suggest that CA processes constitute more than 50 to $65 \%$ of un/fairness incidents in students' classroom experiences. Further, students in this study reported that they exhibited inaction and dissent reactions specifically in the unfairness incidents. In either reaction, students frequently reported they were unable to restore fairness because teachers held a great amount of power. Enacting CA processes with and for students through self- and peerassessments rather than to them (Klenowski, 2009), which was the case in most of the unfair incidents, may help balance this power difference to some extent.

\subsection{Study Limitations}

While findings from this research provide a more comprehensive conceptualization of social psychology of justice within CA contexts, they should be interpreted with this study's scope and with acknowledgement of its limitations. First, although this study followed existing research using CIT (Horan et al., 2010; Houston and Bettencourt, 1999) and adopted a questionnaire method to capture diverse critical incidents, future studies are encouraged to adopt more in-depth qualitative methods such as focus-group interviews to delve deeper into students' fairness conceptualizations. Second, as this study provided initial empirical evidence for conceptualizing CA fairness through students' 
experiences, future studies can extend this work by exploring why students care about CA fairness. For example, we found several incidents where students recounting the memory were not the recipient of un/fairness (i.e. third-party observant), but they perceived un/fairness. Future studies could draw on other theories of social psychology of justice such as the deonance theory (Folger, 2001) to explore whether students' care about fairness because it is a moral virtue to them or for other reasons. We hope that these areas for further research on CA fairness serve to provoke continued studies into the conceptualization of CA fairness through a social psychology of justice perspective as well as other theoretical approaches.

\section{Conclusion}

This study provided initial empirical support for re-conceptualizing fairness in CA contexts through social psychology theory of justice. The findings showed that students perceived CA fairness in relation to justice principles pertaining to the three dimensions of distributive, procedural, and interactional justice. Students' perceptions of CA fairness through these dimensions also significantly influenced their emotional and behavioral outcomes within their classrooms. Students in this study reported a significant number of un/fairness incidents that were associated with teachers' CA practices. This finding shows that students' perception of classroom fairness were considerably influenced by CA practices and their cyclical interplay with teaching practices and classroom interactions. This cyclical and dynamic interplay of CA fairness with the fairness of teaching and classroom interactions brings about experiences of un/fairness for students that potentially influences their learning outcomes. In examining the findings, we also noticed that students use principles of transparency, reasonableness, caring, and timeliness to render un/fairness perceptions. These principles have not already been included in the previous classroom-based conceptualizations of social psychology theory of justice. Additionally, we found students to provide novel interpretations of justice principles including ethicality and adequate, truthful, and justified information that is different from the non-educational definitions of these principles as understood within legal, 
organizational, and health contexts (Greenberg, 2011). Building on the findings of this study and in alignment with recommendations made by Sabbagh and Resh (2016), we call for more empirical studies to investigate students' perception of fairness across diverse cultures and educational systems to develop a more comprehensive portrait of the construct of CA fairness within classroom contexts. 


\section{References:}

Adams, J. S. (1965). Inequity in social exchange. In L. Berkowitz (Ed.), Advances in experimental social psychology (Vol. 2, pp. 267-299 ). New York: Academic Press.

Alm, F., \& Colnerud, G. (2015). Teachers' experiences of unfair grading. Educational Assessment, 20, 132-150. doi:10.1080/10627197.2015.1028620

Bempechat, J., Ronfard, S., Mirny, A., Li, J., \& Holloway, S. D. (2013). She always gives grades lower than one deserves: A qualitative study of Russian adolescents' perceptions of fairness in the classroom. Journal of Ethnographic \& Qualitative Research, 7, 169-187.

Berti, C., Molinari, L., \& Speltini, G. (2010). Classroom justice and psychological engagement: Students' and teachers' representations. Social Psychology of Education, 13, 541-556. doi:10.1007/s11218-010-9128-9

Bies, R. J., \& Moag, J. S. (1986). Interactional justice: Communication criteria of fairness. In R. J. Lewicki, B. H. Sheppard \& M. H. Bazerman (Eds.), Research on negotiation in organizations (Vol. 1, pp. 43-55). Greenwich, CT: JAI Press.

Brookhart, S. M. (2003). Developing measurement theory for classroom assessment purposes and uses. Educational Measurement: Issues and Practice, 22, 5-12. doi:10.1111/j.17453992.2003.tb00139.x

Butterfield, L. D., Borgen, W. A., Amundson, N. E., \& Maglio, A. T. (2005). Fifty years of the critical incident technique: 1954-2004 and beyond. Qualitative Research, 5, 475-497. doi:10.1177/1468794105056924

Buttner, E. H. (2004). How do we dis students?: A model of (dis)respectful business instructor behavior. Journal of Management Education, 28, 319-334. doi:10.1177/1052562903252656

Chory-Assad, R. (2002). Classroom justice: Perceptions of fairness as a predictor of student motivation, learning, and aggression. Communication Quarterly, 50, 58-77. doi:10.1080/01463370209385646 
Chory-Assad, R., \& Paulsel, M. (2004b). Antisocial classroom communication: Instructor influence and interactional justice as predictors of student aggression. Communication Quarterly, 52, 98-114. doi:10.1080/01463370409370184

Chory-Assad, R., \& Paulsel, M. L. (2004a). Classroom justice: Student aggression and resistance as reactions to perceived unfairness. Communication Education, 53, 253-273. doi:10.1080/0363452042000265189

Chory, R., Horan, S. M., \& Houser, M. L. (2017). Justice in the higher education classroom: students' perceptions of unfairness and responses to instructors. Innovative Higher Education, 1-16. doi:10.1007/s10755-017-9388-9

Čiuladienè, G., \& Račelytè, D. (2016). Perceived unfairness in teacher-student conflict situations: students' point of view. Polish Journal of Applied Psychology, 14, 49-66. doi:10.1515/pjap2015-0049

Colquitt, J. A. (2001). On the dimensionality of organizational justice: a construct validation of a measure. Journal of Applied Psychology, 86, 386-400. doi:10.1037/0021-9010.86.3.386

Creswell, J. (2007). Qualitative inquiry and research design: Choosing among five approaches. Thousand Oaks: Sage.

Cronen, V. E., \& Fuller, R. (1976). Freshman perceptions of instructor fairness and expertise: A problem in course evaluation. Communication Quarterly, 24, 45-47. doi:10.1080/01463377609369209

Deutsch, M. (1975). Equity, equality, and need: What determines which value will be used as the basis of distributive justice? Journal of Social Issues, 31, 137-149. doi:10.1111/j.15404560.1975.tb01000.x 
Folger, R. (2001). Fairness as deonance. In SW Gilliland, DD Steiner \& D. Skarlicki (Eds.), Theoretical and cultural perspectives on organizational justice (pp. 3-33). Greenwich, CT: Inf. Age.

Grace, C. C. (2017). Exploring the potential for and promise of incorporating distributive and procedural justices into post-secondary assessment of student learning. Teaching in Higher Education, 22, 304-317. doi:10.1080/13562517.2016.1248388

Greenberg, J. (1987). A taxonomy of organizational justice theories. Academy of Management review, 12, 9-22. doi:10.5465/AMR.1987.4306437

Greenberg, J. (1993). The social side of fairness: Interpersonal and informational classes of organizational justice. In R. Cropanzano (Ed.), Justice in the workplace: Approaching fairness in human resource management (pp. 79-103). Mahwah, NJ: Erlbaum.

Greenberg, J. (2011). Organizational justice: The dynamics of fairness in the workplace. In S. Zedeck (Ed.), Handbook of industrial and organizational psychology (Vol. 3, pp. 271-327). Washington, DC: APA Press.

Holmgren, J., \& Bolkan, S. (2014). Instructor responses to rhetorical dissent: Student perceptions of justice and classroom outcomes. Communication Education, 63, 17-40. doi:10.1080/03634523.2013.833644

Horan, S. M., Chory, R., \& Goodboy, A. (2010). Understanding students' classroom justice experiences and responses. Communication Education, 59, 453-474. doi: $10.1080 / 03634523.2010 .487282$

Houston, M., \& Bettencourt, L. (1999). But that's not fair! An exploratory study of student perceptions of instructor fairness. Journal of Marketing Education, 21, 84-96. doi: $10.1177 / 0273475399212002$

Ishak, Z., \& Fin, L. (2013). Truants' and teachers' behaviors in the classroom. Procedia-Social and Behavioral Sciences, 103, 1228-1237. doi:10.1016/j.sbspro.2013.10.451 
Israelashvili, M. (1997). Situational determinants of school students' feelings of injustice. Elementary School Guidance \& Counseling, 31, 283-292.

Kazemi, A. (2016). Examining the interplay of justice perceptions, motivation, and school achievement among secondary school students. Social Justice Research, 29, 103-118. doi:10.1007/s11211-016-0261-2

Kazemi, A., \& Törnblom, K. (2008). Social psychology of justice: Origins, central issues, recent developments, and future directions. Nordic Psychology, 60, 209-234. doi:10.1027/19012276.60.3.209

Kazemi, A., Törnblom, K., \& Mikula, G. (2015). Justice: Social psychological perspectives. In J. D. Wright (Ed.), International encyclopedia of the social \& behavioral sciences (2nd ed., Vol. 12, pp. 949-955). Oxford: Elsevier.

Kemppainen, J. K. (2000). The critical incident technique and nursing care quality research. Journal of Advanced Nursing, 32, 1264-1271. doi:10.1046/j.1365-2648.2000.01597.x

Klenowski, V. (2009). Australian Indigenous students: Addressing equity issues in assessment. Teaching Education, 20, 77-93. doi:10.1080/10476210802681741

Leventhal, G. (1980). What should be done with equity theory? New approaches to the study of justice in social relationships. In K. Gergen, M. Greenberg \& R. Willis (Eds.), Social exchange: Advances in theory and research (Vol. 9, pp. 27-55). New York: Plenum Press.

Lizzio, A., \& Wilson, K. (2008). Feedback on assessment: Students' perceptions of quality and effectiveness. Assessment \& Evaluation in Higher Education, 33, 263-275. doi:10.1080/02602930701292548

Mazzoli Smith, L., Todd, L., \& Laing, K. (2018). Students' views on fairness in education: the importance of relational justice and stakes fairness. Research Papers in Education, 33, 336353. doi:10.1080/02671522.2017.1302500 
Murdock, T., Miller, A., \& Goetzinger, A. (2007). Effects of classroom context on university students' judgments about cheating: Mediating and moderating processes. Social Psychology of Education, 10, 141-169. doi:10.1007/s11218-007-9015-1

Oppenheimer, R. (1989). Fairness in the classroom: An empirical extension of the notion of organizational justice. Developments in Business Simulation and Experiential Learning, 16. Retrieved from https://journals.tdl.org/absel/index.php/absel/article/view/1867

Rasooli, A., Zandi, H., \& DeLuca, C. (2018). Re-conceptualizing classroom assessment fairness: A systematic meta-ethnography of assessment literature and beyond. Studies in Educational Evaluation, 56, 164-181. doi:10.1016/j.stueduc.2017.12.008

Rasooli, A., Zandi, H., \& DeLuca, C. (2019). Conceptualizing fairness in classroom assessment: Exploring the value of organizational justice theory. Assessment in Education: Principles, Policy, \& Practice. doi:10.1080/0969594X.2019.1593105

Resh, N., \& Sabbagh, C. (2014). Justice, belonging and trust among Israeli middle school students. British Educational Research Journal, 40, 1036-1056. doi:10.1002/berj.3129

Resh, N., \& Sabbagh, C. (2016). Justice and education. In C. Sabbagh \& M. Schmitt (Eds.), Handbook of Social Justice Theory and Research (pp. 349-367). New York: Springer.

Robbins, T. L., \& Jeffords, B. C. (2009). Practising what we preach: Justice and ethical instruction in management education. Ethics and Education, 4, 93-102. doi:10.1080/17449640902861562

Rodabaugh, R. C. (1994). College students' perceptions of unfairness in the classroom. Retrieved from http://digitalcommons.unl.edu/podimproveacad/319.

Sabbagh, C., \& Resh, N. (2016). Unfolding justice research in the realm of education. Social Justice Research, 29, 1-13. doi:10.1007/s11211-016-0262-1

Seifi, Z. (2017, January, 29). The ratio of female and male teachers and students in Iran. Mehr News Agency, Retrieved from https://www.mehrnews.com/news/3890596/ 
Siegrist, J. (2015). Justice and Health. In J. D. Wright (Ed.), International encyclopedia of the social \& behavioral sciences (2nd ed., Vol. 12, pp. 928-931). Oxford: Elsevier.

Thibaut, J. W., \& Walker, L. (1975). Procedural justice: A psychological analysis. Hillsdale, NJ: L. Erlbaum Associates.

Thorkildsen, T. A. (1993). Those who can, tutor: High-ability students' conceptions of fair ways to organize learning. Journal of Educational Psychology, 85, 182. doi:10.1037/00220663.85 .1 .182

Tierney, R. (2013). Fairness in classroom assessment. In J. H. McMillan (Ed.), SAGE handbook of research on classroom assessment (pp. 125-144). Thousand Oaks, CA: SAGE Publications.

Tierney, R. (2014). Fairness as a multifaceted quality in classroom assessment. Studies in Educational Evaluation, 43, 55-69. doi:10.1016/j.stueduc.2013.12.003

Tierney, R. (2016). Fairness in educational assessment. In M. A. Peters (Ed.), Encyclopedia of Educational Philosophy and Theory (pp. 1-6). Singapore: Springer Singapore.

Vogl, E., \& Pekrun, R. (2016). Emotions that matter to achievement: Student feelings about assessment. In G. T. L. Brown \& L. R. Harris (Eds.), Handbook of human and social conditions in assessment (pp. 111-128). New York: Routledge. 
Table 1

\section{Tables}

Distributive Justice Principles, Related Domains, and Frequency

\begin{tabular}{llll}
\hline & Principles & Domains & Frequency \\
\hline Fairness Data & Equality & Classroom Participation & 18 \\
& & Teacher Affect & 23 \\
& Equity & Grading & 45 \\
\multirow{3}{*}{ Unfairness Data } & & Feedback & 2 \\
& Equality & Classroom Participation & 1 \\
& & Teacher Affect & 5 \\
& Equity & Grading & 73 \\
& & Punishment & 6 \\
\hline
\end{tabular}

Table 2

Procedural Justice Principles, Related Domains, and Frequency

\begin{tabular}{|c|c|c|c|}
\hline & Principles & Domains & Frequency \\
\hline \multirow[t]{14}{*}{ Fairness Data } & \multirow[t]{4}{*}{ Consistency } & Attendance Policy & 2 \\
\hline & & Scheduling & 3 \\
\hline & & Assessment & 10 \\
\hline & & Syllabus & 1 \\
\hline & \multirow[t]{2}{*}{ Reasonableness } & Pedagogy & 3 \\
\hline & & Assignment & 14 \\
\hline & Bias Suppression & Assessment & 20 \\
\hline & Transparency & Assessment & 6 \\
\hline & \multirow[t]{3}{*}{ Voice } & Grading & 2 \\
\hline & & Scheduling & 4 \\
\hline & & Syllabus & 5 \\
\hline & \multirow[t]{3}{*}{ Correctability } & Assessment & 4 \\
\hline & & Feedback & 1 \\
\hline & & Pedagogy & 3 \\
\hline \multirow[t]{16}{*}{ Unfairness Data } & \multirow[t]{4}{*}{ Consistency } & Attendance Policy & 5 \\
\hline & & Scheduling & 5 \\
\hline & & Assessment & 16 \\
\hline & & Syllabus & 3 \\
\hline & \multirow[t]{5}{*}{ Reasonableness } & Assessment & 20 \\
\hline & & Assignment & 6 \\
\hline & & Pedagogy & 3 \\
\hline & & Attendance Policy & 7 \\
\hline & & Course Content & 5 \\
\hline & \multirow[t]{2}{*}{ Bias Suppression } & Assessment & 20 \\
\hline & & Punishment & 1 \\
\hline & Transparency & Assessment & 10 \\
\hline & \multirow[t]{2}{*}{ Voice } & Classroom Participation & 1 \\
\hline & & Scheduling & 1 \\
\hline & \multirow[t]{2}{*}{ Ethicality } & Grading & 2 \\
\hline & & Peer Cheating & 1 \\
\hline
\end{tabular}


Table 3

Interactional Justice Principles, Related Domains, and Frequency

\begin{tabular}{|c|c|c|c|}
\hline & Principles & Domains & Frequency \\
\hline \multirow[t]{10}{*}{ Fairness Data } & Respect & Interpersonal Relationship & 22 \\
\hline & & Peer Bias & 1 \\
\hline & & General Feedback & 1 \\
\hline & Caring & Scheduling & 6 \\
\hline & & Cheating & 1 \\
\hline & & Attendance Policy & 2 \\
\hline & & Assessment & 3 \\
\hline & Adequate, Truthful, and & General Feedback & 8 \\
\hline & Justified Information & Pedagogy & 12 \\
\hline & & Instructive Feedback & 9 \\
\hline \multirow[t]{11}{*}{ Unfairness Data } & Respect & Interpersonal Relationship & 51 \\
\hline & & Instructive Feedback & 31 \\
\hline & & General Feedback & 19 \\
\hline & & Punishment & 1 \\
\hline & Caring & Scheduling & 1 \\
\hline & & Assessment & 1 \\
\hline & & Attendance Policy & 5 \\
\hline & Adequate, Truthful, and & Instructive Feedback & 26 \\
\hline & Justified Information & General Feedback & 14 \\
\hline & & Pedagogy & 19 \\
\hline & Timeliness & Grading & 2 \\
\hline
\end{tabular}

Table 4

Affective Reactions to Conditions of Fairness and Unfairness

\begin{tabular}{lll}
\hline & Affective Responses & Frequency \\
\hline Fairness Data & Positive Attitude Toward the Teacher & 128 \\
& Valued & 8 \\
& Hopeful & 7 \\
Unfairness Data & Negative Attitude Toward the Teacher and University System & 196 \\
& Disappointed & 33 \\
& Embarrassed & 32 \\
& Stressed & 5 \\
\hline
\end{tabular}


Table 5

Behavioral Reactions to Conditions of Fairness and Unfairness

\begin{tabular}{lll}
\hline & Behavioral Responses & Frequency \\
\hline Fairness Data & Engagement & 98 \\
& Adaptation & 57 \\
\multirow{2}{*}{ Unfairness Data } & Inaction & \\
& Dissent & 146 \\
& Disengagement & 134 \\
& & 44 \\
\hline
\end{tabular}

